\title{
The effects of a middle-school healthy eating intervention on adolescents' fat and fruit intake and soft drinks consumption
}

\author{
Leen Haerens ${ }^{1,2, *}$, Ise De Bourdeaudhuij ${ }^{1,2}$, Lea Maes ${ }^{3}$, Carine Vereecken $^{3}$, \\ Johannes Brug ${ }^{4}$ and Benedicte Deforche ${ }^{1}$ \\ 'Department of Movement and Sports Sciences, Ghent University, Watersportlaan 2, B-9000 Ghent, Belgium: \\ ${ }^{2}$ Policy Research Centre Sport, Physical Activity and Health: ${ }^{3}$ Department of Public Health, Ghent University, Ghent, \\ Belgium: ${ }^{4}$ Department of Public Health, Erasmus University Medical Centre, Rotterdam, The Netherlands
}

Submitted 13 September 2005: Accepted 15 February 2006

\begin{abstract}
Objectives: To evaluate the effects of a middle-school healthy eating promotion intervention combining environmental changes and computer-tailored feedback, with and without an explicit parent involvement component.

Design: Clustered randomised controlled trial.

Setting: Fifteen West-Flemish (Belgian) middle schools.

Subjects: A random sample of 15 schools with 2991 pupils in 7th and 8th grades was randomly assigned to an intervention group with parental support $(n=5)$, an intervention group without parental support $(n=5)$ and a control group $(n=5)$. In these 15 schools an intervention combining environmental changes with computertailored feedback was implemented. Fat and fruit intake, water and soft drinks consumption were measured with food-frequency questionnaires in the total sample of children.

Results: In girls, fat intake and percentage of energy from fat decreased significantly more in the intervention group with parental support, compared with the intervention alone group (all $F>3.9, P<0.05$ ) and the control group (all $F>16.7, P<0.001$ ). In boys, there were no significant decreases in fat intake ( $F=1.4$, not significant (NS)) or percentage of energy from fat $(F=0.7, \mathrm{NS})$ as a result of the intervention. No intervention effects were found in boys or in girls for fruit $(F=0.5$, NS), soft drinks $(F=2.6, \mathrm{NS})$ and water consumption $(F=0.3, \mathrm{NS})$.

Conclusions: Combining physical and social environmental changes with computertailored feedback in girls and their parents can induce lower fat intake in middleschool girls. However, to have an impact on the consumption of soft drinks and water, governmental laws that restrict the at-school availability of low-nutritive products may be necessary.
\end{abstract}

Keywords

Tailored advice

Environment

Children
In past years dietary behaviours have moved in an unhealthy direction in US youth ${ }^{1,2}$. Also in Europe, children and adolescents have poor dietary habits ${ }^{3-5}$. The transition from childhood into adolescence often results in diets becoming less healthy ${ }^{6}$. Previous research in adolescents has revealed that saturated fat intake is far above recommendations, fruit intake is less than desirable ${ }^{3}$ and soft drinks consumption is too high $^{3}$. An unhealthy diet during adolescence can negatively affect growth and development ${ }^{7}$ and is likely to persist into adulthood ${ }^{8,9}$. High intakes of energy and fat, low intake of fruit and excessive consumption of soft drinks have been associated with higher risk of becoming overweight and obese as well as increased risk for diabetes, hypertension, cancer and cardiovascular diseases ${ }^{2,7,10-14}$.
The immediate and long-term health of adolescents can be improved by the effective promotion of healthy eating in young people $e^{1,7,14}$. Schools are the preferred setting to promote healthy eating in adolescents ${ }^{15}$ because they offer the opportunity to combine nutrition education with changes in the school environment, and parents may also become involved via school-based programmes. Existing evidence indicates that adolescents' food choices are influenced by the food offered in vending machines, shops or at events at school ${ }^{1,16,17}$. Therefore changes in school policies affecting the school environment can improve the opportunities for health-enhancing food choices ${ }^{15,17,18}$. Nutrition education can be offered repeatedly in the classroom with the aim of influencing the motivation, ability and selfconfidence to eat a healthy diet. However, standard 
health education curricula provide youth with generic information. In the last decade a new health education strategy has emerged, computer-tailored feedback ${ }^{19}$, which can be used in classroom nutrition education. Compared with generic class-based health education curricula, computer-tailored messages respond better to the personal motivational and enabling factors that influence adolescents' dietary behaviours ${ }^{20}$. The increased relevance of the messages results in higher attention and motivational impact ${ }^{20}$. Especially for fat intake, computer-tailored interventions have already been found to be more effective than non-tailored approaches ${ }^{20-22}$. Finally, through schools a direct link can also be established with the home environment. Parental influences are important determinants of adolescents' food preferences and adolescents' consumption of healthy food products is associated with the household availability of these products ${ }^{23}$. Therefore it is assumed that parental involvement will increase intervention effects.

To date, only a few school-based interventions have tried to target food behaviours in middle-school children and in these studies no comparisons were made between interventions with and without parental support ${ }^{24}$. $\mathrm{M}$-span, a middle-school intervention aimed at increasing the availability and promotion of lower-fat food choices, was not effective in reducing fat intake at school in adolescents of the intervention schools ${ }^{25}$. The TACOS study (Trying Alternative Cafeteria Options in Schools) was effective in increasing the sales of lower-fat foods and decreasing the sales of high-fat foods, but it was not effective in changing adolescents' self-reported fat intake $^{26}$. The middle-school health education programme used in the Planet Health intervention was effective in girls in increasing fruit and vegetable consumption, but had limited effects on energy from $\mathrm{fat}^{27}$.

The aim of the present study was to evaluate the effects of a healthy food intervention in middle schools, combining changes in the school environment with nutrition education through interactive computer-tailored feedback. It was hypothesised that dietary behaviours would be improved in the intervention groups compared with the control group after 9 months of intervention. Additionally, it was hypothesised that involvement of the parents would increase the effectiveness of the intervention.

\section{Methods}

\section{Subjects}

The present study was a clustered randomised controlled trial. Because of the higher prevalence of overweight and obesity in schools offering technical or vocational training, a random sample of 15 schools out of the 65 schools with technical and vocational education in West-Flanders (Belgium) was selected to participate in this study. The 15 schools were randomly assigned to the intervention or control conditions: intervention with parental support ( $n=5,1226$ pupils), intervention alone $(n=5,1006$ pupils) and a control condition ( $n=5,759$ pupils). The parents of all 2991 pupils in the 7th and 8th grades received an informed consent in which authorisation was enquired for their child to complete measurements. The parents of 151 (5\%) children did not give permission for their child to participate in the study. This resulted in a sample of 2840 boys and girls aged $11-15$ years within 15 schools. Table 1 presents the baseline data of the sample according to condition. The study protocol was approved by the Ethical Committee of Ghent University.

\section{Measurements}

Measures were assessed at the beginning (September 2003) and repeated at the end of the school year (June 2004).

Fat intake was measured with a self-administered questionnaire developed at Ghent University together with the Flemish Institute for Public Health ${ }^{28}$. The questionnaire was validated in a separate study and was found to be sufficiently reliable and valid compared with a dietary record method ${ }^{28}$. The questionnaire consisted of 48 items representing all important sources of fat in the Belgian diet. Pupils were asked how often they consumed these products during a usual day, week or month. A coefficient was calculated, representing the fat content and portion size of each product. This coefficient was multiplied by the frequency of consumption, leading to a fat intake score for each food item. The summation of fat intake scores for all food items led to the total fat intake score $^{27}$. Individual recommended energy intake was calculated from standard recommended energy intake tables based on height, weight, sex, age and activity level $^{29-32}$. This allowed expression of the reported fat intake as a percentage of the total energy intake.

Table 1 Demographics at baseline in the total group and the three conditions

\begin{tabular}{lcccc}
\hline & Total group & I & I & C \\
& $(n=2840)$ & $(n=1226)$ & $(n=1006)$ & $(n=759)$ \\
\hline Age (years), mean \pm SD & $13.1 \pm 0.81$ & $13.04 \pm 0.79$ & $13.24 \pm 0.87$ & $12.85 \pm 0.71$ \\
\% of girls & 36.6 & 40.1 & 15.6 & 58.8 \\
\% lower SES & 67.5 & 68.0 & 78.9 & 52.4 \\
\hline
\end{tabular}

I + P - intervention with parental support; I - intervention alone; C - control group; SD - standard deviation; SES - socio-economic status. 
The percentage of children exceeding the fat intake recommendation of a maximum of $30 \%$ energy from fat was calculated ${ }^{32}$.

A validated food-frequency questionnaire ${ }^{33}$, adapted from the questionnaire used in the HBSC study (Health Behaviour in School-aged Children), was used to assess fruit intake. The question for fruit intake was: 'How many pieces of fresh fruit do you usually eat?' The percentage of children not meeting fruit intake recommendations (2 pieces a day) was calculated. A separate food-frequency questionnaire was used to assess the consumption of soft drinks and water. The questions asked for soft drinks were: 'How many glasses of soft drinks do you drink during a regular school day?' and 'How many glasses of soft drinks do you drink during a regular weekend day?' The same questions were repeated for water.

Demographic factors, i.e. birth date, gender, occupation of father and mother, number of computers at home, were assessed using another self-administered questionnaire. An estimate of socio-economic status of the family was obtained by classifying occupation of the father and mother according to the 'white collar' and 'blue collar' method $^{34}$.

All questionnaires were filled out at school during class hours and under direct supervision of the teachers. At baseline 166 children did not fill out the fruit intake questionnaire, 182 children did not fill out the questionnaire for water and soft drinks consumption and 203 did not fill out the fat intake questionnaire, due to being absent on the day of measurement or changing schools. There were 176 fruit intake questionnaires, 162 water and soft drinks intake questionnaires and 74 fat intake questionnaires missing at the 1-year post-intervention measurements.

\section{The intervention}

The school-based intervention programme was developed to promote healthy food choices and physical activity engagement in order to prevent the increasing prevalence of overweight in children. The intervention was implemented over one school year, beginning in October 2003 and ending in June 2004. Only the healthy food intervention is described below. The effects of the intervention on adiposity indices ${ }^{35}$ and children's physical activity levels (submitted) are reported elsewhere.

\section{Working group}

The healthy food intervention was designed for implementation by the school staff itself. Therefore a working group was composed of the principal, the physical education teacher(s) and other involved teachers. The working group received background information and guidelines on how to address the intervention topics. They received an intervention manual and educational material. Every three months a 1-h meeting with the working group and the research team was held to evaluate the implementation and to plan further actions.

\section{Nutrition interventions}

The food intervention focused on three behavioural changes that were supported by environmental changes: (1) increasing fruit consumption to at least 2 pieces a day; (2) reducing soft drinks consumption and increasing water consumption; and (3) reducing fat intake. Environmental strategies were aimed at increasing the availability of healthy food products and decreasing the availability of unhealthy food items at school. Hence, policies concerning the availability of unhealthy and healthy food products in 7 th and 8 th graders were tackled.

The number of Flemish secondary schools offering fresh fruit is limited, and it is not convenient for adolescents to take fruit with them from home to school ${ }^{17}$. Therefore, to facilitate fruit consumption, fruit was sold once a week at school at low cost or provided free to all 7 th and 8th graders. It was also suggested to offer fruit as a dessert of the school lunch. Most of Flemish secondary schools have stores or vending machines selling soft drinks. Hence, soft drinks are often consumed during breaks and at noon. In addition, soft drinks are often available as a part of the school lunches. Since pupils are more likely to consume soft drinks every day if soft drinks are available at school ${ }^{17}$, the intervention aimed to change the availability and accessibility of soft drinks. Furthermore, schools tried to promote the drinking of water as opposed to soft drinks, by offering it free by means of drinking fountains or at a lower price than soft drinks in shops or vending machines.

Children received information about the improved health consequences of eating fruit as opposed to snacks and drinking water rather than soft drinks. During classes children received the computer-tailored intervention for fat intake ${ }^{22}$ and fruit intake. Questionnaires concerning demographics, food intake and psychosocial determinants of food choices led to a tailored fat and fruit advice. After completing the questionnaire tailored feedback was displayed immediately on the screen. Both the fat and the fruit advice started with a general introduction, followed by normative feedback, which related their intakes to the recommended intakes. The fat advice indicated the sources of fat in the diet and tips were given on how to replace fatty foods. The Transtheoretical Model $^{36}$ was used to define the content and approach of the feedback in the fat advice. Based on the theory of planned behaviour ${ }^{37}$, children received tailored feedback about their intentions, attitudes, self-efficacy, social support, knowledge, benefits and barriers related to their fat intake. In the same way as in the fat advice, the approach of the fruit advice was also based on the Transtheoretical Model. Overall a healthy diet was promoted in an advice of about 5 to 6 pages. Children could either save the advice on the computer or in some 
cases immediately print the feedback. Afterwards they had to complete a task with questions concerning their advice.

Teachers were also encouraged to organise activities like healthy breakfast and educational games, as suggested in the intervention manual. In addition schools were encouraged to develop extra activities supportive to the intervention programme.

\section{Parental involvement}

The goal of the parent involvement was to also create a supportive environment for healthy behaviours away from school. An invitation for an interactive meeting on food habits and the relationship with health was sent to all parents. It is known that parental involvement declines as children move from elementary school through middle school $^{38,39}$ and it is often difficult to get parents to participate in meetings at school ${ }^{40}$. Hence, in order to reach all parents, the information was also communicated in the school paper and newsletters for the parents and was sent to their home address. In these materials parents were made aware of their important role in influencing their children's dietary behaviours.

Most children (97\%) reported to have one or more computers at home. Hence, a CD with the adult computer-tailored intervention for fat intake ${ }^{22}$ was given to all parents to use and complete at home. Parents were thus made aware of their own fat intake and its consequences for health. The advice gave personalised information on how to make changes towards a more healthy diet. Through a brochure parents were informed that their child also used a similar computer-tailored tool, at school in class. They were asked to discuss the feedback that they both received together and to support their child in making the healthy changes suggested in the feedback.

\section{Statistical analyses}

Data were analysed using SPSS 12.0 (SPSS Inc.). Preliminary analyses consisted of descriptive statistics of sample characteristics. Linear mixed models on 1-year post-intervention measures were used to test intervention effects of the school-based healthy diet promotion intervention. Condition and gender were entered as factors in the model. School was nested within condition to take into account school variance. All analyses were adjusted for baseline values, age and socio-economic status. Pre-post analyses on percentage of energy from fat were also adjusted for pre-post differences in physical activity levels since these differences could have caused differences in energy requirements between intervention and control groups. Post hoc analyses were conducted to determine the direction of differences between the conditions. A $P$-value of $<0.05$ was considered statistically significant.

\section{Results}

At baseline on average $69 \%$ of the children exceeded fat intake recommendations and on average $85 \%$ did not meet fruit intake recommendations. Children reported to drink on average 3 glasses of soft drinks each day.

The pre- and post-intervention values of self-reported fat intake, fruit consumption and soft drinks and water consumption are presented in Table 2. The intervention was not effective in increasing self-reported fruit intake and water consumption and no positive intervention effects on soft drinks consumption were found. There was a trend for a significant condition by gender interaction effect for fat intake and percentage of energy from fat. For these variables, the intervention was effective in girls, but not in boys. Table 3 presents pre- and post-test intake levels and F-values of the post hoc analyses in girls. Post boc tests revealed that fat intake and percentage of energy intake from fat decreased significantly more in girls of the intervention with parental support group, compared with both other conditions.

\section{Discussion}

There is ample evidence that children and adolescents in the USA as well as Europe have poor dietary habits ${ }^{2-4}$. The baseline data of the present study clearly confirm these findings for a Belgium-Flanders sample. At baseline very high percentages of boys and girls did not meet fat and fruit intake recommendations and soft drinks consumption was very high. Such dietary habits are putting adolescents at greater risk for chronic problems in adulthood $^{41,42}$. Since food habits are likely to deteriorate further in adolescence ${ }^{9,43}$, there is an urgent need for effective interventions aimed at influencing and improving dietary habits in these youngsters. The present study is therefore somewhat promising, since it showed that a well-planned, theory-based intervention combining personal and environmental change strategies induced some positive dietary changes in girls.

Flemish secondary schools offer a wide range of lownutritive food items in their shops and vending machines ${ }^{17}$. Earlier research pointed out that this unhealthy school environment has a significant negative influence on adolescents' eating behaviour ${ }^{17}$. However, previous intervention studies in middle schools ${ }^{25,26}$ revealed that environmental changes alone were not sufficient to change adolescents' food behaviour and that interventions have more success if personal and environmental factors are targeted ${ }^{44}$. The present intervention was unique in combining computer-tailored feedback with environmental changes for the first time. The intervention had positive effects on fat-related outcomes in girls, but only when parental support was included. Notice there were positive intervention effects only for fat and that this was the behaviour targeted by environmental change as 
Table 2 Pre- and post-intake levels (mean \pm SD) and F-values for effects of a healthy diet intervention

\begin{tabular}{|c|c|c|c|c|c|c|c|}
\hline \multirow[b]{2}{*}{ Condition } & & \multirow[b]{2}{*}{ Pre } & \multirow[b]{2}{*}{ Post } & \multirow[b]{2}{*}{$F_{\text {Condition }}$} & \multirow[b]{2}{*}{$F_{\text {Condition } \times \text { gender }}$} & \multicolumn{2}{|c|}{$F_{\text {Condition }}$} \\
\hline & & & & & & Boys & Girls \\
\hline Fat intake $\left(\mathrm{g} \mathrm{day}^{-1}\right)$ & $\begin{array}{l}\mathrm{I}+\mathrm{P} \\
\mathrm{I} \\
\mathrm{C}\end{array}$ & $\begin{array}{l}111 \pm 48 \\
130 \pm 54 \\
108 \pm 46\end{array}$ & $\begin{array}{l}105 \pm 49 \\
127 \pm 56 \\
104 \pm 45\end{array}$ & 1.3 & $2.4\left(^{*}\right)$ & 1.4 & $9.3^{\star \star \star}$ \\
\hline$\%$ energy from fat & $\begin{array}{l}\mathrm{I}+\mathrm{P} \\
\mathrm{I} \\
\mathrm{C}\end{array}$ & $\begin{array}{l}38.7 \pm 16.3 \\
43.7 \pm 18.1 \\
39.4 \pm 16.2\end{array}$ & $\begin{array}{l}35.1 \pm 16.1 \\
40.2 \pm 17.8 \\
36.7 \pm 15.7\end{array}$ & 1.4 & $2.4\left(^{*}\right)$ & 0.7 & $9.0^{\star \star \star}$ \\
\hline$\%>$ fat recommendations & $\begin{array}{l}\mathrm{I}+\mathrm{P} \\
\mathrm{I} \\
\mathrm{C}\end{array}$ & $\begin{array}{l}65.5 \pm 47.6 \\
74.1 \pm 43.8 \\
67.7 \pm 46.8\end{array}$ & $\begin{array}{l}54.2 \pm 49.9 \\
66.4 \pm 47.3 \\
61.0 \pm 48.8\end{array}$ & 2.8 & 1.5 & NA & \\
\hline Fruit intake (pieces week ${ }^{-1}$ ) & $\begin{array}{l}\mathrm{I}+\mathrm{P} \\
\mathrm{I} \\
\mathrm{C}\end{array}$ & $\begin{array}{l}5.3 \pm 5.3 \\
4.6 \pm 5.0 \\
6.5 \pm 5.0\end{array}$ & $\begin{array}{l}5.4 \pm 5.3 \\
4.4 \pm 4.7 \\
6.0 \pm 4.9\end{array}$ & 0.2 & 1.1 & NA & \\
\hline$\%<$ fruit recommendations & $\begin{array}{l}\mathrm{I}+\mathrm{P} \\
\mathrm{I} \\
\mathrm{C}\end{array}$ & $\begin{array}{l}85.8 \pm 34.9 \\
88.0 \pm 32.5 \\
80.3 \pm 39.8\end{array}$ & $\begin{array}{l}84.3 \pm 36.4 \\
89.3 \pm 30.9 \\
82.1 \pm 38.3\end{array}$ & 0.5 & 0.78 & NA & \\
\hline Soft drinks (glasses day ${ }^{-1}$ ) & $\begin{array}{l}\mathrm{I}+\mathrm{P} \\
\mathrm{I}\end{array}$ & $\begin{array}{l}3.1 \pm 2.4 \\
3.5 \pm 2.5 \\
2.5 \pm 2.2\end{array}$ & $\begin{array}{l}3.1 \pm 2.5 \\
3.9 \pm 2.8 \\
2.6 \pm 2.4\end{array}$ & 2.6 & 0.9 & NA & \\
\hline Water (glasses day ${ }^{-1}$ ) & $\begin{array}{l}\mathrm{I}+\mathrm{P} \\
\mathrm{I}\end{array}$ & $\begin{array}{l}3.4 \pm 2.7 \\
3.1 \pm 2.7 \\
3.7 \pm 2.6\end{array}$ & $\begin{array}{l}3.7 \pm 2.8 \\
3.5 \pm 2.9 \\
4.0 \pm 2.8\end{array}$ & 0.3 & 0.3 & NA & \\
\hline
\end{tabular}

SD - standard deviation; I P - intervention with parental support $(n=1055)$; I intervention alone $(n=685)$; C - control group ( $n=655)$; NA - not applicable because $F_{\text {Condition } \times g e n d e r}$ was not significant.

$\left({ }^{\star}\right), P<0.09 ;{ }^{\star \star \star}, P<0.001$.

well as computer tailoring for both adolescents and parents.

Results from the Planet Health study ${ }^{27}$ after 2 years of intervention indicated that fruit intake increased on average by 0.2 servings a day in girls of the intervention group, while it decreased on average by 0.2 servings a day in the control group. In the present study no positive intervention effects on fruit intake were found. However, it could be argued that a longer intervention period may be necessary to assess significant positive effects, since after 9 months in the present study fruit intake increased by 0.1 servings a week in the intervention with parental support group, while it decreased by 0.5 servings a week in the control group. Declines in fruit intake, as found in the control group, could be due to seasonal variation in availability of fruit when comparing September to June intakes.

Neither in boys nor in girls were there positive intervention effects for soft drinks and water consumption. These findings strengthen our assumption that the combination of a personalised intervention with environmental changes and parental support is essential to access positive intervention effects. The lack of personalised tailored feedback for soft drinks and water consumption could have resulted in an insufficiently intensive intervention for these specific behaviours. Additionally, our experiences were in line with previous research in Flemish secondary schools revealing that financial interests are making school boards resistant to eliminate or reduce the sale of soft drinks during breaks or at lunch ${ }^{17}$. The increasing consumption of sugar-sweetened drinks is considered to contribute to the increasing prevalence of overweight and obesity ${ }^{13}$. Therefore research evaluating the effects of combining personalised interventions with environmental changes on soft drinks and water consumption should be a priority. Furthermore, the huge incomes secondary schools receive from shops and vending machines result in school boards neglecting the importance of a healthy school environment. Therefore

Table 3 Pre- and post-test intake levels (mean \pm SD) and F-values and post hoc test indicators for intervention effects on fat intake and $\%$ energy from fat in girls

\begin{tabular}{|c|c|c|c|c|c|}
\hline Condition & & Pre & Post & Post hoc & $F_{\text {Posthoc }}$ \\
\hline Fat intake $\left(\right.$ g day $\left.^{-1}\right)$ & $\begin{array}{l}\mathrm{I}+\mathrm{P} \\
\mathrm{I} \\
\mathrm{C}\end{array}$ & $\begin{array}{r}97 \pm 38 \\
108 \pm 46 \\
99 \pm 39\end{array}$ & $\begin{array}{l}85 \pm 35 \\
98 \pm 40 \\
95 \pm 40\end{array}$ & $\begin{array}{l}I=C \\
I+P>I \\
I+P>C\end{array}$ & $\begin{array}{l}0.5 \\
6.1^{\star} \\
17.3^{\star \star \star}\end{array}$ \\
\hline$\%$ energy from fat & $\begin{array}{l}\mathrm{I}+\mathrm{P} \\
\mathrm{I} \\
\mathrm{C}\end{array}$ & $\begin{array}{l}37.5 \pm 15.0 \\
41.1 \pm 16.8 \\
38.7 \pm 15.8\end{array}$ & $\begin{array}{l}31.9 \pm 13.6 \\
36.6 \pm 15.2 \\
36.1 \pm 15.5\end{array}$ & $\begin{array}{l}I=C \\
I+P>I \\
I+P>C\end{array}$ & $\begin{array}{c}1.0 \\
3.9^{\star} \\
16.7^{\star \star \star}\end{array}$ \\
\hline
\end{tabular}

$\mathrm{SD}$ - standard deviation; I + P - intervention with parental support ( $n=432)$; I - intervention alone ( $n=108)$; C - control group $(n=392)$.

${ }^{\star}, P<0.05 ;{ }^{* \star *}, P<0.001$. 
one possibility is the restriction of low-nutritive food at school by governmental laws. However, only limited research exists showing that restricting the sale of soft drinks in schools would improve dietary habits in youth ${ }^{45}$. It is possible that adolescents would compensate for the lack of soft drinks at school by the consumption of other sweetened products or by drinking more soft drinks outside school $^{45}$.

In the present study there were clear gender differences in the results. The intervention was effective only in girls and not in boys. These gender differences are in line with the findings from the Planet Health study ${ }^{27}$. In that study ${ }^{27}$ a health education programme was used and limited effects on total energy from fat were found only in girls. Previous research revealed that adult women compared with men were more positive towards the computertailored intervention for fat intake ${ }^{46}$. It is probable that girls were more responsive to the messages of the tailored intervention since in general girls are more attuned to issues of diet ${ }^{47}$. This indicates that combining changes in the school environment with personalised tailored feedback and increasing parental support is the most promising intervention strategy to address fat intake in adolescent girls. However, more research needs to be done on how to address boys

Strengths of the present study are the clustered randomised design with a high participation rate and the combination of a new intervention type, namely a computerised tailored intervention, with environmental changes, which was used for the first time in adolescents. A limitation of the present study is the self-reported character of the measurements. Self-reported measures used to assess dietary intakes of adolescents tend to result in reporting errors ${ }^{48}$ and limited data are available to understand the reporting bias in this age group. Therefore the data in the present study should be treated with considerable caution. In the present study the effect of the whole school intervention was evaluated, while it is also important to study the effects of each component. No studies are available to date that document the effects of personalised tailored food interventions in adolescents. Additional priorities for future research include improving dietary interventions for boys and assessing long-term intervention effects in boys and girls.

In conclusion, the present study provided evidence that the use of school environmental changes to increase the availability of healthy foods at school, together with the use of tailored interventions to motivate and enable healthy choices in girls and their parents, can have positive effects on girls' diets.

\section{Acknowledgements}

This study was supported by the Policy Research Centre Sport, Physical Activity and Health funded by the Flemish Government.

\section{References}

1 Story M, Neumark-Sztainer D, French S. Individual and environmental influences on adolescent eating behaviours. Journal of the American Dietetic Association 2002; 102(3): S40-51.

2 Lytle LA, Kubik MY. Nutritional issues for adolescents. Best Practice \& Research. Clinical Endocrinology \& Metabolism 2003; 17(2): 177-89.

3 World Health Organization. Young people's health in context. Health Behavior in School-aged Children (HBSC) study: international report from 2001/2002 survey. Health Policy for Children and Adolescents 2004; 4:110-9.

4 Cruz JAA. Dietary habits and nutritional status in adolescents over Europe - Southern Europe. European Journal of Clinical Nutrition 2000; 54(1): S29-35.

5 Lambert J, Agostoni C, Elmadfa I, Hulshof K, Krause E, Livingstone B, et al. Dietary intake and nutritional status of children and adolescents in Europe. British Journal of Nutrition 2004; 92(2): S147-211.

6 Lytle LA. In defence of a low-fat diet for healthy children. Journal of the American Dietetic Association 2000; 100(1): $39-41$.

7 Centers for Disease Control and Prevention. Guidelines for school health programs to promote lifelong healthy eating. Journal of School Health 1997; 67(1): 9-26.

8 Kelder SH, Perry CL, Klepp K-I, Lytle LL. Longitudinal tracking of adolescent smoking, physical activity, and food choice behaviours. American Journal of Public Health 1994; 84(7): 1121-6.

9 Lien N, Lytle LA, Klepp K-I. Stability in consumption of fruit, vegetables and sugary food in a cohort from age 14 to age 21 . Preventive Medicine 2001; 33(3): 217-26.

10 Willett WC. Diet and health: what should we eat? Science 1994; 264(5158): 532-7.

11 Reilly JJ, Dorosty AR. Epidemic of obesity in UK children. Lancet 1999; 354(9193): 1874-5.

12 Van Duyn MA, Pivonka E. Overview of the health benefits of fruit and vegetable consumption for the dietetics professional: selected literature. Journal of the American Dietetic Association 2000; 100(12): 1511-21.

13 Ludwig DS, Peterson KE, Gortmaker SL. Relation between consumption of sugar-sweetened drinks and childhood obesity: a prospective, observational analysis. Lancet 2001; 357(9255): 505-8.

14 Matthys C, de Henauw S, Devos C, de Backer G. Estimated energy intake, macronutrient intake and meal pattern of Flemish adolescents. European Journal of Clinical Nutrition 2003; 57(2): 366-75.

15 Wechsler H, Devereaux RS, Davis M, Collins J. Using the school environment to promote physical activity and healthy eating. Preventive Medicine 2000; 31(2): S121-37.

16 Story M. School-based approaches for preventing and treating obesity. International Journal of Obesity and Related Metabolic Disorders 1999; 23(Suppl. 2): S43-51.

17 Vereecken CA, Bobelijn K, Maes L. School food policy at primary and secondary schools in Belgium-Flanders: does it influence people's food habits? European Journal of Clinical Nutrition 2004; 59(2): 271-7.

18 Kubik MY, Lytle LA, Hannan PJ, Perry CL, Story M. The association of the school food environment with dietary behaviours of young adolescents. American Journal of Public Health 2003; 93(7): 1168-73.

19 White MA, Martin PD, Newton RL. Mediators of weight loss in a family-based intervention presented over the internet. Obesity Research 2004; 12(7): 1050-9.

20 Brug J, Campbell M, Van Assema P. The application and impact of computer-generated personalized nutrition education: a review of the literature. Patient Education and Counseling 1999; 36(2): 145-56. 
21 Oenema A, Brug J. Feedback strategies to raise awareness of personal dietary intake: results of a randomized controlled trial. Preventive Medicine 2003; 36(4): 429-39.

22 Vandelanotte C, De Bourdeaudhuij I, Sallis JF, Spittaels H, Brug J. Efficacy of sequential or simultaneous interactive computer-tailored interventions for increasing physical activity and decreasing fat intake. Annals of Behavioral Medicine 2005; 29(2): 138-46.

23 Hanson NI, Neumark-Sztainer D, Eisenberg ME, Story M, Wall M. Associations between parental report of the home food environment and adolescent intakes of fruits, vegetables and dairy foods. Public Health Nutrition 2005; 8(1): 77-85.

24 Bautista-Castano I, Doreste J, Serra-Majem L. Effectiveness of intervention in the prevention of childhood obesity. European Journal of Epidemiology 2004; 19(7): 617-22.

25 Sallis JF, McKenzie TL, Conway TL, Elder JP, Prochaska JJ, Brown M, et al. Environmental interventions for eating and physical activity: a randomized controlled trial in middle schools. American Journal of Preventive Medicine 2003; 24(3): 209-17.

26 French SA, Story M, Fulkerson JA, Hannan P. An environmental intervention to promote lower-fat food choices in secondary schools: outcomes of the Tacos study. American Journal of Public Health 2004; 94(9): 1507-12.

27 Gortmaker SL, Peterson K, Wiecha J, Sobol AM, Dixit S, Fox $\mathrm{MK}$, et al. Reducing obesity via a school-based interdisciplinary intervention among youth: Planet Health. Archives of Pediatrics \& Adolescent Medicine 1999; 153(4): 409-18.

28 Vandelanotte C, Matthys C, De Bourdeaudhuij I. Reliability and validity of a computerized questionnaire to measure fat intake in Belgium. Nutrition Research 2004; 24(8): 621-31.

29 World Health Organization (WHO). Energy and Protein Requirements. Report of a Joint Food and Agriculture Organization/WHO/United Nations University Expert Consultation. Technical Report Series No. 724. Geneva: WHO, 1985.

30 Schofield WN, Schofield C, James WPT. Basal metabolic rate: review and prediction. Human Nutrition. Clinical Nutrition 1985; 39(Suppl. 1): 1-96.

31 Commission of the European Communities. Proposed nutrient and energy intakes for the European Community: a report of the Scientific Committee for Food of the European Community. Nutrition Reviews 1993; 51(7): 209-12.

32 National Council on Nutrition. Dietary Recommendations for Belgium. Brussels: Ministry of Social Affairs, Public Health and Environment, 2000

33 Vereecken CA, Maes L. A Belgian study on the reliability and relative validity of the Health Behaviour in School-Aged Children food-frequency questionnaire. Public Health Nutrition 2003; 6(6): 581-8.
34 Hollingshead AB. Two-Factor Index of Social Position. New Haven, CT: Yale University Press, 1957.

35 Haerens L, Deforche B, Maes L, Stevens V, Cardon G, De Bourdeauhuij I. Body mass effects of a physical activity and healthy food intervention in middle schools. Obesity Research 2006; 14(5): 847-54

36 Prochaska JO, DiClemente CC, Norcross JC. In search how people change. Applications to addictive behaviors. The American Psychologist 1992; 47(9): 1102-14.

37 Ajzen I. From intentions to actions: a theory of planned behavior. In: Kuhl J, Beckman J, eds. Action-control: From Cognition to Behavior. Heidelberg: Springer, 1985; 11-39.

38 Eccles JS, Harold RD. Parent-school involvement during the early adolescent years. Teachers College Record 1993; 94(3): 568-87.

39 Paulson SE, Sputa CL. Patterns of parenting during adolescence: perceptions of adolescents and parents. Adolescence 1996; 31(122): 369-81.

40 Nader PR, Sallis JF, Abramson IS, Broyles SL, Patterson TL, Rupp JW, et al. Family-based cardiovascular risk reduction education among Mexican- and Anglo-Americans. Family and Community Health 1992; 15(1): 57-74.

41 World Health Organization (WHO). Diet, Nutrition and the Prevention of Chronic Diseases. Report of a Joint WHO/Food and Agriculture Organization Expert Consultation. WHO Technical Report Series No. 916. Geneva: WHO, 2003.

42 Licence K. Promoting and protecting the health of children and young people. Child: Health, Care and Development 2004; 30(6): 623-35.

43 Bertheke Post G, de Vente W, Kemper HC, Twisk JW. Longitudinal trends in and tracking of energy and nutrient intake over 20 years in a Dutch cohort of mean and women between 13 and 33 years of age: the Amsterdam growth and health longitudinal study. British Journal of Nutrition 2001; 85(3): 375-85.

44 Hoelscher DM, Evans A, Parcel G, Kelder S. Designing effective nutrition interventions for adolescents. Journal of the American Dietetic Association 2002; 102(3 Suppl.): S52-63.

45 Finkelstein E, French S, Variyam JN, Haines PS. Pros and cons of proposed interventions to promote healthy eating. American Journal of Preventive Medicine 2004; 27(3 Suppl.): $163-71$.

46 Vandelanotte C, De Bourdeaudhuij I, Brug J. Acceptability and feasibility of an interactive computer-tailored fat intake intervention in Belgium. Health Promotion International 2004; 19(4): 463-70.

47 McVey G, Tweed S, Blackmore E. Correlates of weight loss and muscle-gaining behaviour in 10 - to 14 -year-old males and females. Preventive Medicine 2005; 40(1): 1-9.

48 Livingstone MB, Robson PJ, Wallace JM. Issues in dietary intake assessment of children and adolescents. British Journal of Nutrition 2004; 92(Suppl. 2): S213-22. 